\title{
O CINEMA NA LITERATURA CONTEMPORÂNEA: UMA EXPERIÊNCIA INTERMIDIÁTICA
}

Maria Angẽlica Amâncio Santos*

Resumo: Nesta pesquisa, analisam-se dois romances contemporâneos em que o cinema está essencialmente presente, seja pela forma, seja pelo tema: Neige noire (1974), do canadense Hubert Aquin, e Cinéma (1999), do francês Tanguy Viel. O intuito do trabalho é, assim, o de investigar, nessas obras, as possibilidades de troca intermidiática entre a literatura e o cinema, com enfoque para a expansão do fazer literário a partir de seu diálogo com a arte cinematográfica.

Palavras-chave: Intermidialidade. Literatura contemporânea de língua francesa. Literatura e cinema.

\section{Filmic writing e o romance Neige noire, de Hubert Aguin}

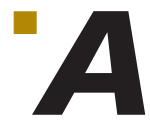

literatura é uma das maiores fontes de inspiração para o cinema, desde o princípio de sua história, no final do século XIX. Ela lhe fornece o argumento para a elaboração de tramas de sucesso, o modelo para sua classificação em gêneros - como o romance, a comédia, o suspense -, além de uma série de recursos dos quais o cinema mais tarde se apropriaria, como a montagem paralela (cf. BURCH, 1990).

Por sua vez, também a literatura soube nutrir-se do cinema. A conquista de uma linguagem própria, por parte da sétima arte, influi na narrativa escrita, especialmente no romance, que utiliza artificios e recursos de composição próprios do cinema, para gerar a ilusão de simultaneidade, movimento, descontinuidade. Busca-se, desse modo, a descrição da visualidade e a concretude da câmera. Persegue-se a objetividade da imagem - ainda que se saiba ser esta

\footnotetext{
Universidade de São Paulo (USP) - São Paulo - SP - Brasil. Université Sorbonne Nouvelle (Paris III) - Paris - França. Bolsista Capes. E-mail: gellyamancio@yahoo.com.br
} 
relativa -, visivel na imediatez da palavra, na objetividade da linguagem, cada vez mais substantiva e fluida.

Experiências assim, que se valem de tal estreitamento das relações entre palavra e imagem, acentuam-se principalmente a partir da década de 1960, com a novelização, o cine-romance e a filmic writing. Esta pode ser associada a romances como O medo do goleiro diante do pênalti, de Peter Handke (1988 [1971]), e O beijo da mulher aranha, de Manuel Puig (1995). Após o fim da Segunda Guerra Mundial, autores como esses inauguram outro gênero, outra forma, em que o leitor é tratado também como espectador; em que a literatura cria uma nova realidade onírica, que pode se manifestar tanto na estrutura narrativa quanto na própria diegese.

O romance Neige noire (1974), do canadense Hubert Aquin, enquadra-se também nessa categoria. Em seu livro, o escritor, que também foi diretor e roteirista, incorpora o cinema tanto ao conteúdo quanto, explicitamente, à forma, pois a estrutura do texto constrói-se pela imitação da linguagem filmica. Ao mesmo tempo, Aquin não perde de vista o seu "desejo de romance", como denomina Anne Élaine Cliche (1992): é justamente ao desmontar a máquina romanesca, semeando em todo o texto marcas características de um roteiro de cinema, que ele constrói um grande romance, capaz de problematizar a estética dos gêneros:

Nicolas volta para o quarto, refrescado. Senta-se em uma poltrona, diante de Sylvie, que ainda dorme. Flashback: grande plano de Nicolas; nós o vemos erguer a cabeça por sobre o ombro de Sylvie, depois afastar-se dela com um esgar de dor. Filmar essa cena de dia, para mostrar as fotos e gravuras coladas nas paredes do apartamento de Nicolas.

O espectador entendeu, já há algum tempo, que as relações sexuais tornaram-se bastante frustrantes para Nicolas ${ }^{1}$ (AQUIN, 1997, p. 6-7)2 .

Observa-se, nesse trecho, a remissão ao cinema, pelos vocábulos "grande plano", "cena" e pelo verbo "filmar", que parece destinado a um diretor potencial, possivelmente o próprio personagem. Nota-se também a existência de uma progressão temporal que encadeia as ações, caracterizadas com a visualidade que também é usada para descrever o cenário. O cinema vislumbra-se igualmente no flashback e, claro, pela menção direta a um espectador, no lugar de um leitor, que decodificaria a série de planos, em vez de ler uma sequência de frases.

Tipograficamente também já se identifica a diferença entre Neige noire e os romances tradicionais, já que o texto não é exatamente dividido em parágrafos, mas em blocos, que evocam a estrutura do roteiro cinematográfico. Tal semelhança intensifica-se ao longo da obra, pois as falas dos personagens não surgem entre aspas ou antecipadas por travessões, mas evocando os diálogos teatrais ou cinematográficos:

\footnotetext{
No original: "Nicolas revient dans la chambre, tout frais. Il prend place dans un fauteuil, face à Sylvie qui dort toujours. Flashback: gros plan de Nicolas; on le voit lever la tête au-dessus de l'épaule de Sylvie, puis se dégager d'elle en grimaçant de douleur. Tourner cette scène le jour, ce qui permet de montrer les photos et les gravures accrochées aux murs de l'appartement de Nicolas./Le spectateur a compris que, depuis quelque temps, les rapports sexuels sont devenus bien frustrants pour Nicolas."

2 Esta e as demais traduções de Aquin são nossas.
} 
EVA

A única?

\section{Sr. LEWANDOWSKI}

Sim, a única a dividir o segredo comigo. Um desses dias, nós poderíamos almoçar juntos... ${ }^{3}$ (AQUIN, 1997, p. 197) ${ }^{4}$.

Todos esses índices cinematográficos, comuns na composição da chamada filmic writing, enquadram-se no que a teórica alemã Irina Rajewsky chama de "referências intermidiáticas" (intermediale Bezüge). A partir da observação das práticas intermidiáticas, e em busca de se estabelecer uma teoria uniforme para cada uma, Rajewsky as agrupou em três categorias: 1. a intermidialidade no sentido estrito de transposição midiática (Medienwechsel), que inclui as adaptações filmicas de textos literários, as novelizações e outras transformações midiáticas; 2. a intermidialidade no sentido estrito de combinação de mídias ( $M e$ dienkombination), em que se enquadram a ópera, o filme, o teatro, a iluminura, a história em quadrinhos; 3. a intermidialidade no sentido estrito de referências intermidiáticas (intermediale Bezüge), que corresponde, por exemplo, à referência, num texto literário, a certo filme, gênero filmico ou cinema em geral - sendo este, é claro, o caso do romance de Hubert Aquin.

Haveria ainda outra distinção fundamental do primeiro em relação ao segundo e ao terceiro grupos: os dois últimos visam a uma intermidialidade intracomposicional, e não extracomposicional, como na transposição intermidiática. Ou seja, de acordo com o teórico Werner Wolf, citado pela autora, na combinação e na referência intermidiática, tem lugar a "participação direta ou indireta em mais de uma mídia [...] na significação e/ou estrutura de uma dada entidade semiótica" (WOLF apud RAJEWSKY, 2012b, p. 59). A participação direta ocorreria quando a articulação midiática se apresenta em toda a sua materialidade, constituindo a obra. Já no caso da participação indireta, outra mídia seria evocada, o observador teria a impressão de sua presença, num processo de "como se", não contando, concretamente, com a mídia a que se alude: como na pintura fotorrealista ou na filmic writing:

O autor literário escreve, como Heinz B. Heller explica, "como se ele tivesse os instrumentos do filme à sua disposição, o que na realidade não acontece". Usando os meios específicos das mídias à sua disposição, o autor de um texto não pode, por exemplo, "verdadeiramente" fazer um zoom, editar, dissolver imagens, ou fazer uso de técnicas e regras reais do sistema cinematográfico; ele necessariamente permanece dentro da sua própria mídia verbal, isto é, textual. Nessa impossibilidade de ir além de uma única mídia, uma diferença midiática se revela - uma fenda intermidiática - que um texto intencionalmente esconde ou exibe, mas que, de qualquer forma, pode ser transposta somente no modo figurativo do "como se" (RAJEWSKY, 2012a, p. 28).

\footnotetext{
3 No original: "ÉVA/La seule?/M.LEWANDOWSKI/Oui, la seule à partager ce secret avec moi. Un de ces jours, nous pourrions peut-être déjeuner ensemble..."

4 Optou-se por não utilizar o recuo nessa citação, pois o intuito é o de reproduzir a tipografia usada no livro.
} 
Segundo a autora, é justamente essa ilusão que distingue os fenômenos intramidiáticos dos intermidiáticos: ainda que a mídia apenas evoque ou imite outro sistema, cujas especificidades é incapaz de reproduzir com seus recursos, as sensações relativas a outra mídia são despertadas no receptor. Esses efeitos teriam gerado expressões metafóricas como "escrita cinematográfica" (filmic writing) ou "musicalização da literatura", que influenciaram fortemente o debate literário sobre as relações entre as mídias antes mesmo do advento do conceito de intermidialidade.

Nota-se, portanto, que, embora invadido pela linguagem cinematográfica, Neige noire não é um roteiro. Passagens consideravelmente poéticas, como "Sylvie [...] nada veste além do sono" (AQUIN, 1997, p. 7) ${ }^{5}$, invadem frequentemente o texto, lembrando o leitor disso. O livro apenas dá a "impressão" de roteiro, apresentando-se como um simulacro ou mesmo uma paródia do gênero. Aquin sequer emprega a alcunha "roteiro fictício" ou "filme imaginário". O diálogo com o cinema, nesse texto, tem pretensões que ultrapassam a da inovação estrutural.

Para André Soares Vieira (2007, p. 74), as marcas do roteiro cinematográfico dizem respeito a um mundo em que o visual não mais representa um fator de coerência e harmonia e em que "o apelo ao cinema apenas corrobora o bombardeio de pseudoinformações fragmentárias e desconexas veiculado pela mídia moderna". Assim, o emprego do visual, nesse caso, pela irrupção de efeitos icônicos aleatórios, quer suscitar no leitor questões a respeito da rotulação do gênero romance, apresentado na capa, em relação à linguagem cinematográfica presente no interior do livro, além de sublinhar a distância que separa as palavras das imagens, numa sociedade como a atual, que sempre se deixa dominar pela vertigem imagética do cinema, da televisão e, hoje, da internet.

Em termos de conteúdo, esse, que é o último romance de Hubert Aquin, apresenta uma trama pseudopolicial, empreendida por um roteirista-cineasta, que também é detetive e assassino. Não há solução do crime, muito menos punição do responsável, como seria comum nos romances policiais. A obra é composta pela contínua confusão entre realidade e ficção, dentro de um mundo fragmentado e incoerente, de ilusões de ótica, distorções e anamorfoses. A linguagem é o primeiro instrumento a arrastar o leitor para dentro desse turbilhão de sentidos e imprecisões.

Isso ocorre porque, além da referência ao cinema, que é predominante, o escritor quebequense lança mão de um rico repertório intertextual ${ }^{6}$, composto por ecos literários, citações, enxertos e alusões intertextuais, como à obra de Shakespeare, evocada pela ideia de "narrativa encaixada" e de play within a play hamletiana:

Corte para a sala de ensaios número 5, nível B, Sede da Rádio-Canadá. Ensaia-se um drama de 90 minutos para a televisão: Hamlet de William Shakespeare. Mas Nicolas não desempenha o papel principal, confiado, como se deve, a Jean-Louis Roux. [...] Nicola senta-se perto de um colega.

NICOLAS

O que vai acontecer com o papel de Hamlet quando Jean-Louis tiver a idade necessária para interpretar o espectro? 


\section{ATOR}

Quê isso, você devia saber que Jean-Louis Roux jamais aceita interpretar gente morta...

Os dois riem um pouco. Nicolas atua como Fontinbras...

(Fortinbras... O que significaria nesse momento? Aliás, quem, dentre os espectadores, sabe que Fortinbras é príncipe da Noruega e filho de Fortinbras, soberano da Noruega e antigo inimigo do pai de Hamlet? É claramente dificil traduzir essas rivalidades monárquicas visualmente) (AQUIN, 1997, p. 8)7.

Identifica-se, no trecho transcrito, outra peculiaridade estilística: a inserção da nota no corpo do texto, entre parênteses, em forma de comentários, que vão tomando proporções cada vez maiores, ocupando até quatro páginas - como nas de número 211 a 215 -, chegando ao ponto de assinalarem o próprio desfecho do romance. Se, no excerto reproduzido, seu uso é metalinguístico, relativo à possivel (in)compreensão do espectador face à identidade dos personagens, em outros momentos, tais notas introduzem, por exemplo, o discurso filosófico, que também permeia o livro, em reflexões sobre a passagem inevitável do tempo, seu fluxo incessante, que confere a sensação de atordoamento à existência. Longe de exercerem papel secundário para a compreensão da obra, portanto, as notas determinam a própria essência.

Como se pode perceber, a presença da linguagem cinematográfica nesse romance compõe uma constelação de referências, que visam questionar as fronteiras entre o literário e o extraliterário, a ficção e a realidade. Porém, o caráter cinematográfico se destaca, pois "a descrição de um filme disponibiliza novos modos de escritura ligados à necessidade de dizer um mundo em constante mutação no qual categorias como tempo e espaço não mais possuem as dimensões até então fixadas pela imagem" (VIEIRA, 2007, p. 74).

Desse modo, cabe avaliar o quanto o diálogo com o roteiro é sintomático. $\mathrm{Na}$ trama, o roteiro escapa ao controle do roteirista e o filme não é realizado. Uma vez que os roteiros são, a priori, textos destinados a se transformarem, o sentimento experimentado pelo personagem é o da frustração. Contudo, o próprio livro, um romance-roteiro, situa-se nesse entrelugar metamórfico que, transcendendo o gênero específico, aproxima-se igualmente da instabilidade movediça do tempo, objeto de sua principal reflexão.

\section{A écr(An)iture ${ }^{8}$ de Tanguy Viel, em Cinéma}

É precisamente o tempo o elemento subjacente em uma análise como esta, que avalia o diálogo intermidiático entre a literatura e o cinema em obras contemporâneas - pois foi o século XX o primeiro a gerar escritores que não conheceram o mundo

7 No original: "Couper à la salle de répétition numéro 5, niveau B, Maison de Radio-Canada. On y répète une dramatique de 90 minutes pour la télévision: Hamlet de William Shakeaspeare. Mais Nicolas ne joue pas le role titre qu'on a confie, comme il se doit, à Jean-Louis Roux. [...] Nicolas s'assied près d'un collègue./NICOLASIQu'adviendra-t-il du rôle d'Hamlet quand Jean-Louis aura l'âge qu'il faut pour interpréter le spectre?/COMÉDIENIAllons, tu devrais savoir que Jean-Louis Roux n'accepte jamais d'interpréter les morts.../Les deux rient un peu ensemble. Nicolas joue le rôle de Fortinbras.../(Fortinbras... Tout doit-il signifier à ce point? D’ailleurs qui, parmi les spectateurs, sait que Fortinbras est prince de Norvège et fils de Fortinbras, souverain de Norvège et ancien ennemi du père d'Hamlet? II est assurément difficile de traduire ces rivalités dynastiques en prises de vues. [...]"

8 Expressão empregada por Ari Blatt (2006), que mescla os termos "écriture" (escrita/escritura) e "écran" (tela), em referência ao romance de Viel. 
sem a presença do cinema, para os quais a experiência cinematográfica é um fator inevitável, que pode, com maior ou menor naturalidade, integrar sua produção literária. Para o escritor Claude Simon (1998, p. 6, tradução nossa),

[...] é evidente que, na formação de homens e mulheres deste século lo século $X X]$, o cinema e suas diversas técnicas (travelling, panorâmica, zoom, plano geral etc.) tiveram tanta ou mais influência do que os autores clássicos cujos versos aprenderam a recitar no colégio ${ }^{9}$.

Cinéma, de Tanguy Viel, segunda obra em estudo neste trabalho, é publicado emblematicamente em 1999, o último ano do século XX, e se trata, segundo Jean-Max Colard, de um singular representante de uma "littérature d'après", ou seja, de uma literatura posterior ao cinema. O romance realiza a mescla sensivelmente contemporânea entre mídias, sendo irrigado pela linguagem cinematográfica a que alude, explicitamente, por meio da referência ao filme "O jogo mortal" (Sleuth, 1972, Estados Unidos/Inglaterra), de Joseph L. Mankiewcz. No livro, um espectador aficionado pelo filme em questão, ao qual assistiu dezenas de vezes, descreve minuciosamente a trama, como se recontasse a história ao leitor ou, melhor, a si mesmo:

Um carro esportivo, o carro vermelho de Milo Tindle, na aleia que leva ao castelo, ao solar que vemos de frente, imponente. Tindle é seu nome, é um inglês, que estaciona no pátio do solar, sobre o cascalho, com seu carro esportivo vermelho e seu terno justo, muito na moda nos anos setenta. Ele sai de seu carro esportivo vermelho, (com suas iniciais escritas do lado direito, sobre a pintura: M.T. como Milo Tindle $)^{10}$ (VIEL, 1999, p. 9) ${ }^{11}$.

À primeira vista, o livro pode ser classificado como uma novelização, ou seja, uma passagem do filme para o formato de romance. Essa forma de adaptação, semelhante à já conhecida tradução intermidiática da literatura para o cinema, associa-se à primeira categoria proposta por Irina Rajewsky, a de intermidialidade no sentido estrito de transposição midiática (Medienwechsel).

Segundo Jan Baetens (2016), especialista no estudo da novelização ${ }^{12}$, o gênero surge nos anos 1910, na imprensa americana e francesa, que publicava uma série de folhetins com objetivos publicitários. Hoje, mais de um século depois, o gênero sofreu modificações, mas continua marginalizado enquanto literatura, sendo permanentemente associado à indústria cultural e enfrentando quatro principais entraves: institucional, estético, semiológico e prático.

O primeiro deles diz respeito à origem da obra, que é, na grande maioria dos casos, uma encomenda do produtor cinematográfico, o qual espera que o livro responda a uma estrutura comercial específica. Dessa maneira, o autor encara uma dificuldade estética, que é a exigência de que seu romance seja o mais fiel

9 No original: "Il est évident que dans la formation de tout homme comme femme de ce siècle le cinéma et ses diverses techniques (travelling, panoramique, zoom, gros plan, etc.) ont pour le moins autant d'influence que les auteurs classiques dont il a appris au collège à réciter les vers".

10 No original: "Une voiture de sport, la voiture rouge de Milo Tindle, qui roule dans l'allée qui mène au château, au manoir qu'on voit de face et qui en impose. Tindle, c'est son nom, c'est un Anglais, et il se gare dans la cour du manoir, sur le gravier, avec sa voiture de sport rouge, et sa vest étriquée très à la mode dans les années soixante-dix. II en sort, de sa voiture rouge (avec ses initiales inscrites sur le côté, sur l'aile droite, rajoutées par-dessus la peinture, c'est écrit: M.T., comme Milo Tindle)".

11 Esta e as demais traduções de Viel são nossas.

12 Optou-se por utilizar o termo "novelização", mais sonoramente semelhante a seus correspondentes no francês e no inglês respectivamente, novellisation e novelization. Outra expressão possível seria "romancização". Tem-se também notícia do uso de "romantização", menos preferível, no entanto, por evocar a ideia de Romantismo. 
possivel ao filme que lhe dá origem. O novelizador tem, assim, pouca liberdade e muito pouco tempo para trabalhar, já que o texto precisa estar nas livrarias no mesmo momento em que o filme chega às salas de cinema. A restrição temporal é, consequentemente, um entrave prático, que se associa ao semiológico: muitas vezes, o escritor sequer assiste ao filme, tendo acesso somente a seu roteiro. Torna-se, então, praticamente impossivel preocupar-se com a transposição de informações relativas à mídia filmica, como a trilha sonora e o figurino dos atores. Não é por acaso, portanto, que a novelização ainda é considerada um subproduto do filme e uma espécie menor de adaptação.

No entanto, segundo o próprio Baetens (2008, p. 19), o gênero é reinventado no trabalho de Viel, pois o autor problematiza o papel de leitor e espectador, e é sensivel ao conflito psicológico instaurado no filme. Prova disso é a narração não ser a recriação fiel da obra de Mankiewcz: o narrador desafia a ordem dos fatos, adianta informações, comenta a engenhosidade do diretor, salienta detalhes:

[...] Milo Tindle não está morto, de fato, e disso nós sabemos, ou melhor, não, nesse momento do filme, não se sabe de nada, cremos efetivamente que ele está morto, mas ele não está morto, e eu me explico rapidamente. É por isso que eu destaquei há pouco a importância do número de tiros: dois, depois aquele para matar Milo. Então três ${ }^{13}$ (VIEL, 1999, p. 67).

Diante desses detalhes que o narrador considera essenciais, percebe-se a relação obsessiva do personagem com "O jogo mortal". Ele revela, por exemplo, a irritação com os amigos aos quais exibira o filme e que não observaram certas informações ou não julgaram a obra tão genial quanto ele a considera: "[...] não é o filme que não é formidável, mas eles, somente eles que estão longe, muito longe de serem formidáveis, e que vêm, fiéis a si mesmos, projetar sua mediocridade sobre a tela" ${ }^{14}$ (VIEL, 1999, p. 93), afirma. Ao mesmo tempo, esse narrador sem corpo, sem nome e sem história revela, paulatinamente, seu conhecimento de certos recursos filmicos, seu gosto pela arte cinematográfica como um todo: "Ele lhe entrega um uísque (Andrew a Milo), de modo que pensamos que é aí que a história começa, como num filme de Hitchcock ${ }^{15}$, em que o álcool dá ritmo à intriga para melhor enganar os personagens"16 (VIEL, 1999, p. 30). O narrador chega a analisar o sentido da morte e da encenação no cinema, a partir de uma cena que descreve:

[...] não existe falsa morte possível no cinema, ou melhor; no cinema, finge-se estar morto, mas se, no interior do filme, finge-se estar morto, então, de certa forma, acaba-se morrendo de verdade, dado o fato, simplesmente, de que no cinema uma falsa morte é uma verdadeira morte ${ }^{17}$ (VIEL, 1999, p. 71).

13 No original: "[...] Milo Tindle n'est pas mort en vrai, et cela on le sait, ou plutôt non, à ce moment du film on n'en sait rien, on croit effectivement qu'il est mort pour de vrai, mais il n'est pas mort, et je m'explique rapidement. C'est pour ça que j'ai noté tout à l'heure l'importance du nombre de coups de feu: deux, plus celui pour tuer Milo. Donc trois".

14 No original: "[...] ce n'est pas le film qui manque d'être formidable, mais eux, uniquement eux qui sont loin, très loin d'être formidables, et qui viennent, fidèles à eux-mêmes, projeter leur médiocrité sur l'écran".

15 A título de curiosidade, vale mencionar que, em 2010, em parceria com Florent Chavouet, Viel lança Hitchcock, par exemple, livro em que um suposto crítico de cinema, com trejeitos bastante semelhantes aos do narrador de Cinéma, elogia a cinematografia de Alfred Hitchcock e de outros diretores, como Ingmar Bergman e Roberto Rossellini (VIEL; CHAVOUET, 2010).

16 No original: "Et lui tend un whisky (Andrew, à Milo), de sort qu'on se dit que c'est parti comme dans un film de Hitchcock, quand l'alcool rythme l'intrigue pour mieux piéger les personnages".

17 No original: "[...] il n'y a pas de fausse mort possible au cinéma, ou pour dire mieux: au cinéma, on fait comme si on était mort, mais si, en plus, à l'intérieur du film, on fait comme si on était mort, alors en quelque sorte on finit par être mort pour de vrai, du fait, tout simplement, qu'au cinéma une fausse mort est une vraie mort". 
O leitor vai percebendo que o personagem tem o filme no centro de sua vida, que dele partem suas análises cinematográficas, que ele pauta suas escolhas pessoais. Em dado momento, o narrador reconhece que a maioria das coisas que sabe ele aprendeu com o filme, e afirma: "não tenho vida além do filme, sou um homem morto sem Sleuth, o título original em inglês, para mim não é mais o nome de um filme, é o nome de um amigo, eu digo Sleuth como diria Andrew"18 (VIEL, 1999, p. 96). A partir daí, e ao longo das quase 20 páginas finais do livro, há uma mudança tipográfica significativa: o itálico deixa de ser empregado junto ao título do filme e ele passa a ser chamado simplesmente de Sleuth, personificado, como se fosse, de fato, um ser humano, um amigo. O narrador chega a confessar que pede desculpas a Sleuth quando o deixa sozinho, que o cumprimenta quando volta e que faz questão de deixá-lo sempre em um lugar confortável, onde não faça muito frio nem muito calor (VIEL, 1999).

Quanto ao filme em si, trata-se de um thriller labirintico, evocando o romance policial, como o livro de Hubert Aquin. A trama se passa, quase completamente, em um espaço fechado, a mansão de Andrew (Laurence Olivier), autor de romances detetivescos. O escritor contracena com Milo Tindle (Michael Caine), barbeiro de origem italiana, que está tendo um caso com sua esposa, Marguerite. A mulher, no entanto, é apenas evocada, bem como uma quarta personagem, Téa, de cuja existência só se tem notícia pelo diálogo entre os protagonistas. Pode-se resumir o enredo a um jogo, no qual tanto Andrew quanto Milo lançam mão de estratégias diversas, no intuito de ludibriar um ao outro.

É importante atentar às inúmeras transmidiações ${ }^{19}$ relativas a essa obra, a começar pela sequência dialógica literatura + cinema (e também teatro), que a acompanha, em sentido amplo: de peça a roteiro, de roteiro a filme (tendo o romance no centro), de filme a livro (tendo o filme no centro) - e, novamente, peça e filme. A história tem origem na peça teatral homônima, de Antony Shaffer, que foi sucesso na Brodway entre 1970 e 1973. O próprio dramaturgo roteirizou o texto para Mankiewcz, em 1972. Na trama, o literário se apresenta, já que um dos protagonistas tenta aplicar o que aprendera com os personagens de seus romances policiais, para se vingar do amante da esposa. Duas décadas depois, o filme transforma-se em romance/novelização, pelas mãos de Tanguy Viel, ressurgindo, então, em mise en abyme, uma história dentro da outra, uma mídia dentro da outra, e transformando o leitor no que Claude Murcia (2007, p. 410) chama de "spectalecteur" ("espectaleitor").

Há ainda outras encenações da obra, como a versão brasileira Em nome do jogo, de Gustavo Paso, que esteve em cartaz em 2012, nas principais capitais do pais. E houve, em 2007, uma refilmagem, realizada pelo diretor Keneth Branagh, o qual atualiza o cenário da trama, substituindo a parafernália lúdica do original por um sistema tecnológico ultramoderno. O remake, traduzido no Brasil como Um jogo de vida ou morte, tem Jude Law no papel de Milo, e o próprio Michael Caine, ex-Milo, agora atuando como Andrew. A inversão reproduz aspectos importantes do enredo, como a representação e o jogo de duplos. Como mencionado, a trama pode ser resumida a uma sequência de artificios emprega-

18 No original: "[...] je n'ai pas de vie à côté du film, je suis un homme mort sans Sleuth, oui, Sleuth, le titre original du film en anglais, pour moi ce n'est plus un nom de film, c'est le nom d'un ami, je dis Sleuth comme je dirais Andrew".

19 O termo é empregado no sentido explorado por Lars Elleström e analisado por Figueiredo (2016, p. 47), para quem "a transmidiação é resultante da midiação de um conteúdo anteriormente midiado, ou seja, submetido a um processo de materialização por meio de uma mídia técnica". 
dos pelos dois protagonistas para enganar um ao outro. No início do filme, por exemplo, Andrew convence Milo a se fantasiar de palhaço e simular um roubo. Mais tarde, este retorna, disfarçado de Detetive Doppler, em busca de uma revanche - ou de duas, como destaca o protagonista de Cinéma:

Detective Inspector Doppler, ou o anagrama quase perfeito de Plodder, e Plodder, eu preciso dizer, é o inspetor idiota que encontramos nos romances policiais de Andrew, é o grande inimigo do famoso detetive, o grande inimigo de Saint John Lord Merridew. Então há duas vinganças que se confundem, matando dois coelhos com uma cajadada só, tanto Milo que se vinga de Andrew quanto Plodder que se vinga de Merridew ${ }^{20}$ (VIEL, 1999, p. 87).

Doppler, como o narrador ressalta, significa também "duplo", em alemão, o que reforça a duplicidade do personagem ${ }^{21}$. É a vez, então, do aristocrata Andrew ser enganado pelo arrivista Milo - inversão que se renova, portanto, no filme de Branagh. Essa troca constante de papeis, na trama, mistura a "vida real" dos personagens, no filme, à ficção da literatura produzida por Andrew. Provoca-se, assim, como ocorre no romance de Aquin, uma contínua problematização dos conceitos de realidade e fantasia.

O filme também foi remediado pelo francês Pierre Bismuth, coincidentemente em $1999^{22}$, ano da publicação de Cinéma. Sem conhecer a obra de Viel, o artista plástico realizou diversas projeções do filme de Mankiewcz, em televisores e locais diferentes - cômodos de uma casa, hotel, loja de eletrodomésticos etc. -, filmando cada uma delas, no intuito de realizar um vídeo em que cada plano correspondesse a uma dessas exibições. O vídeo não chegou a abarcar todo o filme, totalizando 17 minutos e sendo exibido em galerias de arte, como a Bugada \& Cargnel, em Paris.

De acordo com Jean-Max Colard, a obra de Bismuth explicita a realidade do olhar contemporâneo, já que os espectadores não mais se reúnem na sala de cinema, e o espetáculo deixa de ser uma experiência partilhada, fragmentando-se. Em comparação com o romance de Viel, percebe-se que, em ambos, o filme permanece inalterado, imperturbável, central - é o mundo a redor que se desintegra (COLARD, 2015, p. 85).

Nesse processo, também as restrições de gênero se desfazem. Viel - como Hubert Aquin, em Neige noire - transgride as amarras da forma literária, compondo um romance que pode ser também considerado novelização, intriga policial, resenha crítica ou o solilóquio de um espectador aficionado pelo filme de Mankiewcz. Nessa experiência intermidiática, a clausura espacial do filme é transposta para a clausura temporal do livro, em que o "espectaleitor" erra por esse tempo abstrato da narração, desconectado da vida e da temporalidade histórica, no qual a obsessão do personagem dita as regras, "a partir dos meandros e das bifurcações de seu texto, na busca impossivel do absoluto do filme, inalcançável, irredutível” (MURCIA, 2007, p. 412).

20 No original: “Detective Inspector Doppler, ou l'anagramme presque exacte de Plodder, et Plodder, il faut que je dise, c'est l'inspecteur idiot qu'on retrouve dans les romans policiers d'Andrew, c'est le grand ennemi du détective célèbre, le grand ennemi de Saint John Lord Merridew. Alors il y a bien deux vengeances qui se confondent, faisant d'une pierre deux coups, aussi bien Milo qui se venge d'Andrew, et Plodder qui se venge de Merridew".

21 O narrador também elogia a astúcia de Mankiewcz, que, nos créditos de abertura do filme, escreve: "Apresentando Alec Cawthorne, como Inspetor Doppler", no intuito, é claro, de não revelar esse segredo ao espectador, que é enganado junto a Andrew (VIEL, 1999, p. 69).

22 Disponível em: <http://www.maryboonegallery.com/artist_info/pages/bismuth/detail2.html>. Acesso em: 14 set. 2016. 
Essa busca inalcançável a que se refere Murcia é a da própria transposição da mídia cinematográfica em mídia verbal, literária. Pode-se comparar esse processo ao da tradução linguística, acerca da qual o narrador faz diversas observações ao longo do texto. Ele admite a impossibilidade de traduzir, na lingua francesa, expressões ditas em inglês, no original. Muitas vezes, ele as reproduz, porque considera este um idioma mais dramático, mais cinematográfico, talvez: "Mas nada vale mais do que a simplicidade. Nothing succeeds like simplicity, diz Andrew, em inglês, é sempre em inglês que se diz, todo mundo sabe disso, as maiores mortes são encenadas em inglês"23 (VIEL, 1999, p. 60). Mesmo assim, ele insiste. Insiste em tentar transpor não apenas a maioria dos diálogos para o francês, como também em transformar em palavras, em um caderno expressamente comprado para isso, a história do filme que tanto o fascina.

No entanto, por se tratarem de mídias distintas, a conversão total dos elementos cinematográficos para a literatura é impossível. Essa lacuna se faz ver pelas inúmeras interrupções do narrador, que parece contar o filme a partir de uma reprodução em VHS, pausando, rebobinando, avançando ações. Ele tenta, então, preencher os vazios dessa impossibilidade de adaptação integral do filme por meio de intervenções críticas, comentários e dos lampejos de intimidade que irrompem no texto.

O personagem, portanto, não copia, mas recicla, criando uma obra nova. Vislumbra-se, na singeleza de seu caderno de anotações, o predecessor para o que hoje se conhece como fanfictions - narrativas ficcionais escritas por fãs que se apropriam de personagens e enredos originários de suas configurações midiáticas favoritas (séries, jogos, filmes, quadrinhos) e as divulgam na internet. Ao mesmo tempo, Tanguy Viel, enquanto escritor, é também responsável por esse processo de reinvenção do filme de Manckiewcz.

Em entrevista a Maxime Pierre (2008), o autor confessa que usara, de fato, o filme como uma fonte de inspiração, em um momento de escassez de ideias, admitindo utilizar o cinema também como modelo de coesão para seus romances. Ele realiza, portanto, o que Jeanne-Marie Clerc e Monique Carcaud-Macaire (2004, p. 182) chamam de "escritura transmodal", ao se aproveitar, estética e filosoficamente, da impossibilidade real de transposição do filme para o livro, com a finalidade de criar. Esse processo criativo em diálogo com o cinema conduz, assim, às considerações finais deste artigo.

\section{CONSIDERAÇÕES FINAIS}

Na capa de Cinéma, há um contraste tipográfico marcante, que é a disposição do título do livro, escrito em caixa alta, com letras grandes, acima da palavra "romance", que surge com todas as letras minúsculas, discreta, quase invisível $^{24}$. A capa parece, assim, uma provocação: ela problematiza, em primeiro lugar, a possibilidade de se definir o gênero romance, em si tão maleável, e remete, igualmente, ao próprio quebra-cabeça formal que é o livro em questão, mescla de definições possiveis - como é também o romance Neige noire, de Hubert

\footnotetext{
23 No original: "Mais rien ne vaut la simplicité. Nothing succeeds like simplicity, dit Andrew, en anglais, c'est toujours ce qu'on dit, c'est très connu, les plus grandes morts se jouent en anglais".

24 Essa tipografia é comum nos livros publicados pela Éditions de Minuit. Optamos, no entanto, por explorá-la de outra maneira,
} neste trabalho, acreditando-a potencialmente representativa na obra em questão. 
Aquin, híbrido com o roteiro, a narrativa policial e tantos outros modos de intertextualidade, conforme mencionado.

Esse desdobramento do gênero romanesco remete à diluição de fronteiras entre as formas, tanto intra quanto intermidiáticas, exigindo um público cada vez mais versátil, que saiba ser leitor e espectador juntamente, sem se perder nos meandros de um fluxo possivelmente sem fim. Como observado neste artigo, a mídia cinematográfica tem representado, para a literária, uma nova perspectiva para falar de si mesma, pensar a si mesma, recriar-se. A exemplo dos personagens centrais do filme narrado em Cinéma, ou como na "narrativa encaixada" de Neige noire, tais mídias tendem a continuar encontrando-se nesse labirinto, em que um caminho desemboca no outro, uma forma é contida por outra, sem parênteses, e a literatura segue fantasiando-se de cinema, e vice-versa, continuamente.

\section{CINEMA IN CONTEMPORARY LITERATURE: AN INTERMEDIAL EXPERIENCE}

Abstract: In this research, I analyze two contemporary novels in which cinema is essentially present, in the structure or as a topic: Neige noire (1974), written by the Canadian Hubert Aquin, and Cinéma (1999), by the French author Tanguy Viel. My purpose, in this paper, is to investigate possible intermedial exchanges between literature and cinema, in these works, emphasizing literary gains in its dialogue with the cinematographic arts.

Keywords: Intermediality. Francophone and contemporary literature. Literature and cinema.

\section{REFERÊNCIAS}

AQUIN, H. Neige noire. Québec: Bibliothèque Québécoise, 1997 [1974].

BAETENS, J. La Novellisation. Du film au roman. Liège: Les impressions nouvelles, 2008.

BAETENS, J. Création et novellisation. Disponivel em: <http://www.wikicreation.fr/upload/Jan_Baetens_fr.pdf>. Acesso em: 14 out. 2016.

BLATT, A. Remake: appropriating film in Tanguy Viel's Cinéma. Disponível em: <http:/ / www.tandfonline.com/doi/abs / 10.1080/17409290500242498\#.VznfWfkrLIU>. Acesso em: 13 out. 2016.

BURCH, N. La Lucarne de l'infini. Naissance du langage cinématographique. Paris: Nathan, 1990.

CLERC, J.-M.; CARCAUD-MACAIRE, M. L'Adaptation cinématographique et littéraire. Paris: Klinchsieck, 2004.

CLICHE, A. É. Le Désir du roman (Hubert Aquin, Réjean Ducharme). Montreal: Editora XYZ, 1992.

COLARD, J.-M. Une littérature d'après. "Cinéma" de Tanguy Viel. Dijon: Les Presses du Réel, 2015. 
FIGUEIREDO, C. A. P. Em busca da experiência expandida: revisitando a adaptação por meio da franquia transmidiática. 2016. $238 \mathrm{f}$. Tese (Doutorado em Letras)-Universidade Federal de Minas Gerais, Belo Horizonte, 2016. Disponivel em: <http://www.bibliotecadigital.ufmg.br/dspace/handle/1843/ECAP-A8JFED>. Acesso em: 5 abr. 2017.

HANDKE, P. O medo do goleiro diante do pênalti. Tradução Zé Pedro Antunes. São Paulo: Brasiliense, 1988 [1971].

MURCIA, C. La mixité de la fabrique: du matériau filmique à l'élaboration du personnage. In: LAVOCAT, F.; MURCIA, C.; SALADO, R. (Org.). La fabrique du personnage. Paris: Honoré Champion, 2007. p. 401-413.

PIERRE, M. Entretien avec Laurent Mauvignier et Tanguy Viel, "Affronter la crise: outils et stratégies". Publifarum, n. 8, 2008. Disponivel em: <http://publifarum.farum.it/ezine_articles.php?id=97>. Acesso em: 15 jan. 2016.

PUIG, M. El beso de la mujer araña. Buenos Aires: Seix Barral, 1995.

RAJEWSKY, I. O. Intermidialidade, intertextualidade e "remediação": uma perspectiva literária sobre intermidialidade. Tradução Thaïs Flores Nogueira Diniz e Eliana Lourenço de Lima Reis. In: DINIZ, T. F. N. (Org.). Intermidialidade e estudos interartes. Belo Horizonte: Editora UFMG, 2012a. v. 1, p. 15-45.

RAJEWSKY, I. O. A fronteira em discussão: o status problemático das fronteiras midiáticas no debate contemporâneo sobre intermidialidade. In: DINIZ, T. F. N.; VIEIRA, A. S. (Org.). Intermidialidade e estudos interartes: desafios da arte contemporânea. Belo Horizonte: Rona Editora, Fale/UFMG, 2012b. v. 2, p. 51-73. SIMON, C. Entrevista concedida a C. Michel e R. Robert. Scherzo, n. 3, p. 5-11, abr. 1998.

VIEIRA, A. S. Escrituras do visual. Santa Maria: Editora UFSM, 2007.

VIEL, T. Cinéma. Paris: Les Éditions de Minuit, 1999.

VIEL, T.; CHAVOUET, F. Hitchcock, par exemple. Paris: Naïve, 2010.

Recebido em dezembro de 2016. Aprovado em janeiro de 2017. 